\section{Only a train can mask another train}

\author{
Behrouz Salehian $\mathrm{MD}^{1}$, Melvin Yan $\mathrm{DO}^{2}$
}

\section{CASE 1}

A 36-year-old man presented with fever, abdominal pain and diarrhea reportedly lasting for the past three months. Originally an immigrant from Mexico, he had been living in California for the past four years and made a recent trip back to Guerrero, Mexico.

On admission, the patient was febrile $\left(41^{\circ} \mathrm{C}\right)$, hypotensive (94/54 $\mathrm{mmHg})$, tachycardic (118 beats/min) and tachypneic (36 breaths/min). Multiple bilateral cervical and axillary lymph nodes were palpated. Other findings included crackles in the bases of both lungs and a large mass in the left hypochondrium.

Initial laboratory tests were significant, showing a partial pressure of $\mathrm{O}_{2}$ of $36 \mathrm{mmHg}$ in arterial blood while breathing room air, a total leukocyte count of $3.8 \times 10^{9} / \mathrm{L}$ (neutrophils $79 \%$, bands $5 \%$, lymphocytes $14 \%$ and monocytes $1 \%$ ), a hemoglobin level of $102 \mathrm{~g} / \mathrm{L}$, hematocrit of $32 \%$, a mean corpuscular volume of $78.7 \mathrm{fL}$ and a platelet count of $273 \times 10^{9} / \mathrm{L}$. A lumbar puncture was normal, with no organisms seen on smear, and India ink was negative with negative bacterial cultures. A tuberculin skin test was also negative. Serology (both ELISA and Western blot assays) was negative for HIV. The initial chest $\mathrm{x}$-ray was abnormal with a wide mediastinum, but without infiltrates. Further work-up included an abdominal ultrasound, which revealed a hypoechogenic mass adjacent to the tail of the pancreas.

Pancytopenia developed during the admission. A computed tomography scan of the chest showed the presence of mediastinal and peribronchial lymph nodes, bilateral pleural effusions and consolidation in both lung bases. A computed tomography scan of the abdomen showed an irregular large mass near the pancreatic tail encasing the splenic vein and multiple ill-defined densities in the periaortic area.

What diagnostic procedure was performed, and what was the diagnosis?

Continued on next page

${ }^{1}$ Charles R Drew University of Medicine and Science; ${ }^{2}$ San Francis Medical Center, Los Angeles, California, USA

Correspondence: Dr Behrouz Salehian, Charles R Drew University of Medicine and Science, Department of Medicine MP 11, 12021 South Wilmington Avenue, Los Angeles, California 90509, USA. Telephone 310-668-6057, fax 310-763-8929, e-mail besalehi@cdrewu.edu

Received and accepted for publication December 14, 2005

\section{Doctor, there's a tadpole in my feces!}

Rosemary Drisdelle ART, Kevin R Forward MD FRCPC

\section{CASE 2}

A6-year-old male resident of a coastal Nova Scotia comAmunity presented to his family physician after he noted moving objects in his feces (Figure 1). Although concerned and revolted, he was asymptomatic. He was worried that the organisms were an intestinal parasite he had passed in his stool. The organisms were approximately $2.5 \mathrm{~cm}$ long and resembled tadpoles. The fecal sample was sent to the Parasitology Section at the Queen Elizabeth II Health Sciences Centre in Halifax, Nova Scotia, for identification.

What was the diagnosis?

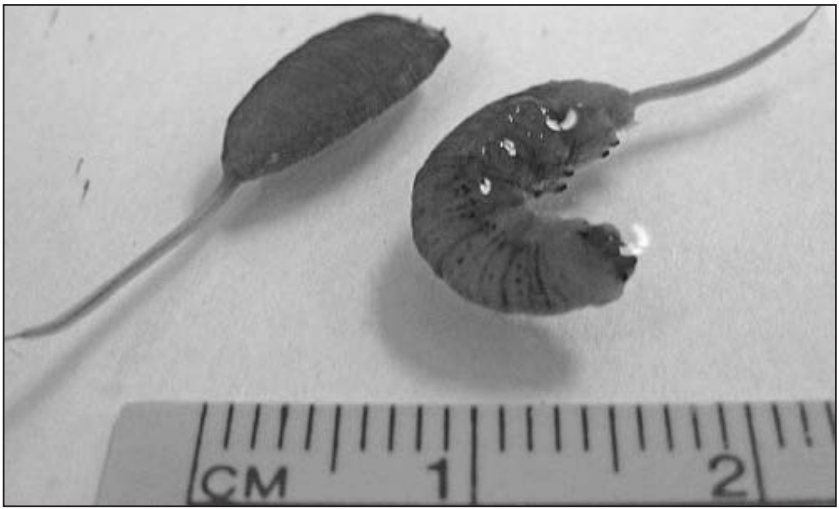

Figure 1) Rat-tailed Eristalis larvae

Continued on next page
Division of Microbiology, Department of Pathology and Laboratory Medicine, Queen Elizabeth II Health Sciences Centre, Halifax, Nova Scotia

Correspondence: Rosemary Drisdelle, Division of Microbiology, Queen Elizabeth II Health Sciences Centre, 5788 University Avenue, Halifax, Nova Scotia B3H 1V8. Telephone 902-473-6887, fax902-473-4432, e-mail victord@accesswave.ca

Received and accepted for publication November 10, 2005 


\section{Case 1 - continued}

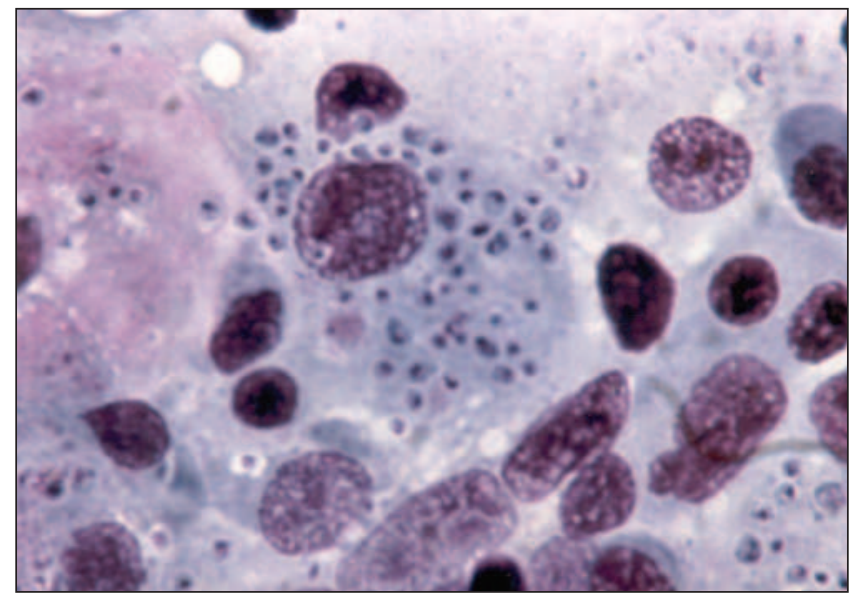

Figure 1) Bone marrow biopsy demonstrating the presence of a monocyte (centre) containing intracytoplasmic inclusions, each with a halo, characteristic of Histoplasma capsulatum. A few plasmacytes and lymphocytes are visible (hematoxylin and eosin stain, original magnification $\times 40$ )

\section{DIAGNOSIS}

A bone marrow biopsy revealed Histoplasma capsulatum inclusions in monocytes (Figure 1), and a bone marrow culture confirmed the diagnosis of histoplasmosis. After an initial full recovery following amphotericin $\mathrm{B}$ therapy and then oral itraconazole and monthly follow-up, he was readmitted five months later with a recurrence of histoplasmosis. Repeat HIV serology was positive, indicating recent HIV seroconversion.

\section{DISCUSSION}

This patient had fever of unknown origin, and his final diagnosis of disseminated histoplasmosis is considered unusual without an established state of immunosuppression. He was HIV-negative in both the ELISA and Western blot assays at initial hospital admission; however, he was HIV-positive five months later. At the time of the symptomatic histoplasmic infection, the patient most likely had a very early HIV infection but was still antibody-negative. His initial two-month flulike illness, consisting of fever, chills, fatigue and decreased appetite, could have represented early acute HIV viral syndrome. A literature review failed to disclose other reports of acute HIV seroconversion coincident with the onset of histoplasmosis as an opportunistic infection. The usual time from HIV viral inoculation to seroconversion is between two weeks and six months (1). It took us five months to establish the diagnosis of HIV seroconversion in our patient. However, the patient became symptomatic with an $H$ capsulatum infection during the seroconversion period, which, in retrospect, could have been a combination of symptoms arising from the simultaneous infections. If we had obtained plasma for HIV RNA viral load at the time of his initial presentation, we could have confirmed the HIV seroconversion despite an initial negative serology.

\section{REFERENCE}

1. The AIDS incubation period in the UK from a national register of HIV seroconverters. UK Register of HIV Seroconverters Steering Committee. AIDS 1998;12:659-67.

\section{Case 2 - continued}

\section{DIAGNOSIS}

The objects were tentatively identified as the 'rat-tailed' maggots of a syrphid, or drone fly, of the genus Eristalis. Our patient was advised to collect several subsequent stool specimens on different days. No drone fly larvae were found in the patient's subsequent stool samples.

On further questioning regarding the circumstances under which the original larvae were found, we learned that the stool in question had not been flushed into a closed septic system, but had remained in an 'open cistern' for a brief period before being discovered by another individual. In all likelihood, the organisms were already present in the cistern and migrated to the fecal 'food supply' prior to their discovery.

No further treatment or follow-up was recommended.

\section{DISCUSSION}

Also known as a hover fly or flower fly, the drone fly is quite large and resembles a honeybee. The adult fly visits flowers and collects nectar; however, the larval stage of this insect is far less fanciful - the female fly lays hundreds of eggs on decaying organic matter, including feces (1).

The developing larvae feed on decomposing organic material. The tail-like structure is actually a breathing tube, allowing the larvae to flourish in very wet environments and to feed on submerged material with their breathing tubes extended to the surface (2). These larvae may invade farm out-buildings in large numbers in search of a dry location when they are ready to pupate (1).

It has been suggested that humans acquire Eristalis tenax intestinal myiasis by ingesting the fly eggs, or early-stage maggots, in contaminated food or water $(2,3)$. The larvae then develop in the intestine, feeding on luminal contents. However, there is some question as to whether they can survive the anaerobic environment of the intestine. Alternatively, it has been suggested that the female fly may deposit eggs in the perianal area and the newly hatched maggots crawl into the rectum and develop there, extending their breathing tubes through the anus like a diver's snorkel (4).

Since the beginning of the twentieth century, there have been sporadic reports of individuals passing the larvae of Eristalis tenax in stool $(2,3,5,6)$. One of the most recently reported cases (2) involved a 42-year-old woman in south Australia, who recovered small numbers of the larvae from her stool repeatedly over a period of approximately 14 days. She had no physical symptoms. Most commonly, patients report anal discomfort and anal pruritis $(4,6)$. Dizziness and nonspecific abdominal pain have also been described $(3,6)$.

Dorland's Illustrated Medical Dictionary defines 'myiasis' as "a condition caused by infestation of the body by fly maggots" (7). The definition implies that the larvae are continuing their development on, or in, the host. No species of fly, however, requires passage through the human intestine for completion of its life cycle, and most fly larvae passed in the stool are incidental.

The term 'intestinal pseudomyiasis' has been used to describe the accidental entrapment of a swallowed larva passing, alive or dead, through the digestive tract $(4,8,9)$. 


\section{Case 2 - continued}

Dorland's defines 'pseudomyiasis' as "the presence of fly maggots in the digestive tract due to ingestion; if present in large numbers, they may cause diarrhea and other symptoms" (7).

Our case, in which the larvae are presumed to have migrated to stool after it was passed, might more correctly be called intestinal pseudo-pseudomyiasis; however, we propose the less perplexing 'failure to flush syndrome'.

\section{REFERENCES}

1. University of Kentucky Entomology. Rat-tailed maggots and moth flies. <www.uky.edu/Agriculture/Entomology/entfacts/livestc/ ef500.htm> (Version current at April 28, 2006).

2. Whish-Wilson PB. A possible case of intestinal myiasis due to Eristalis tenax. Med J Aust 2000;173:652.

3. Aguilera A, Cid A, Regueiro BJ, Prieto JM, Noya M. Intestinal myiasis caused by Eristalis tenax. J Clin Microbiol 1999;37:3082.

4. Zumpt F. The problem of intestinal myiasis in humans. S Afr Med J 1963;37:305-7.

5. Hall MC. A note regarding myiasis, especially that due to syrphid larvae. Arch Intern Med 1918;21:309-12.

6. Hira PR. Rectal myiasis: First report on a case due to the rat-tailed larva of Eristalis tenax in Africa. East Afr Med J 1977;54:224-6.

7. Dorland's Illustrated Medical Dictionary. 28th ed WB Saunders Company; 1994. Pseudomyiasis p 1379; Myiasis p 1091.

8. Intestinal myiasis - Washington. Morb Mortal Wkly Rep $1985 ; 34: 141-2$.

9. Kenney M, Eveland LK, Yermakov V, Kassouny DY. Two cases of enteric myiasis in man. Pseudomyiasis and true intestinal myiasis. Am J Clin Pathol 1976;66:786-91.

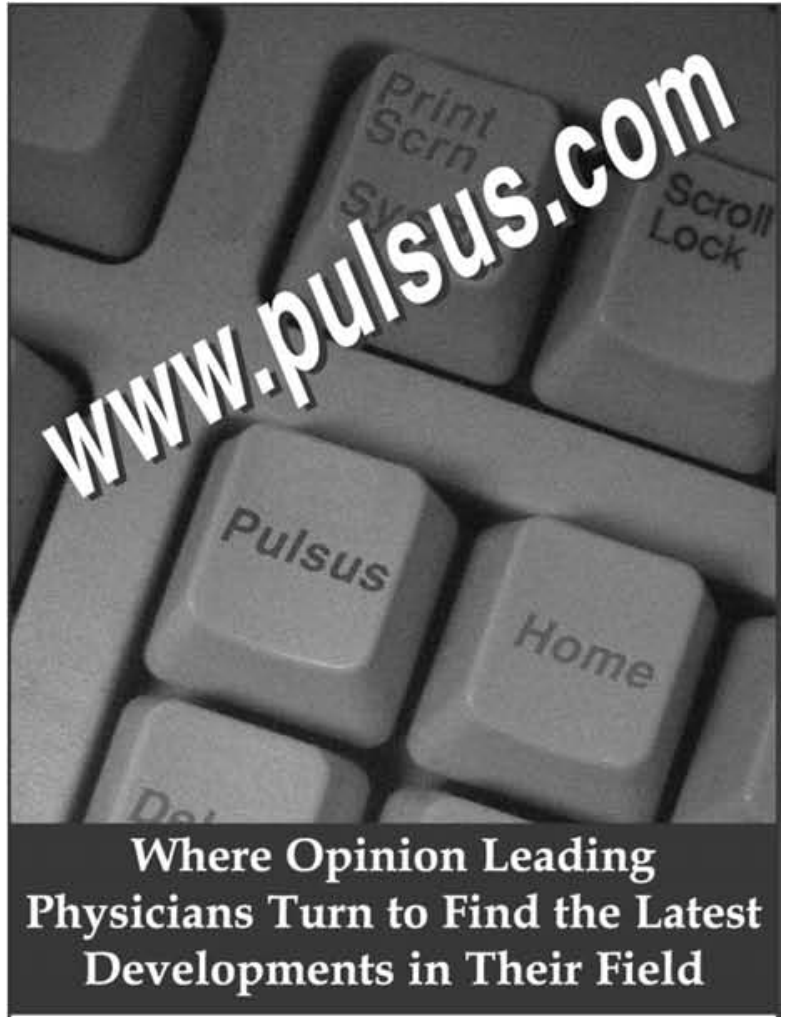

The Canadian Journal of Cardiology The Canadian Journal of Gastroenterology

Paediatrics \& Child Health

Canadian Respiratory Journal

The Canadian Journal of Infectious Diseases \& Medical Microbiology

Pain Research \& Management

The Canadian Journal of Plastic Surgery

Experimental \& Clinical Cardiology

Access to FULL TEXT articles for subscribers and affiliated society and association members (with access codes)

ABSTRACTS available to all

NOW AVAILABLE

Back issues of

Pulsus journals at

shop.pulsus.com

Register Today!

www.pulsus.com 


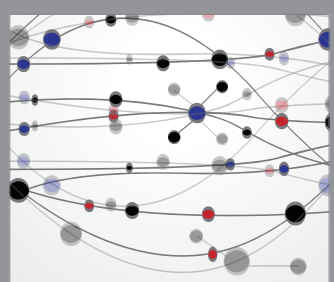

The Scientific World Journal
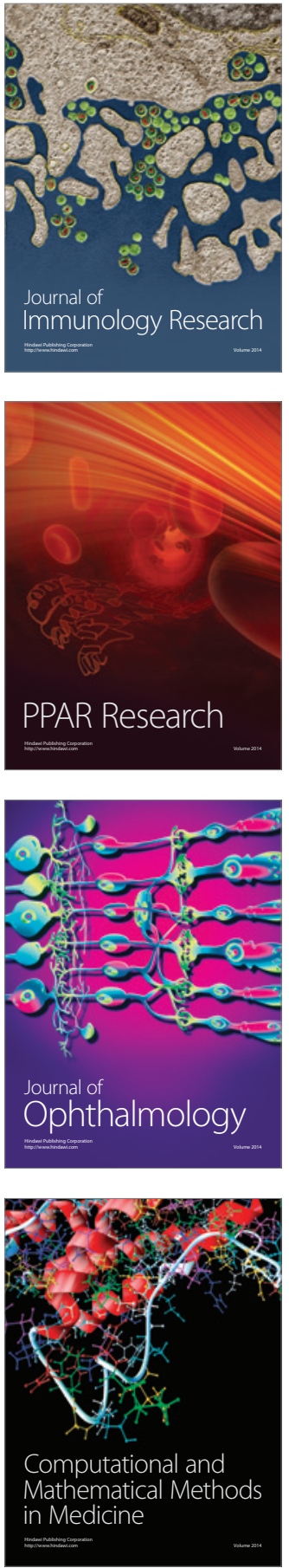

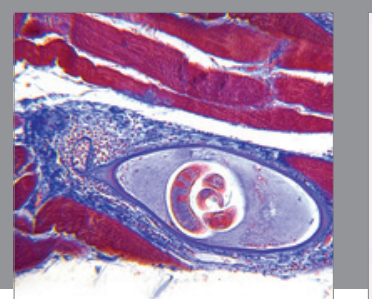

Gastroenterology Research and Practice

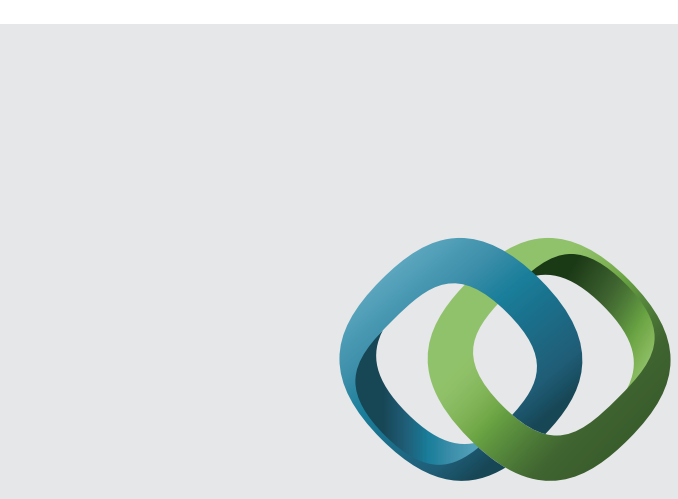

\section{Hindawi}

Submit your manuscripts at

http://www.hindawi.com
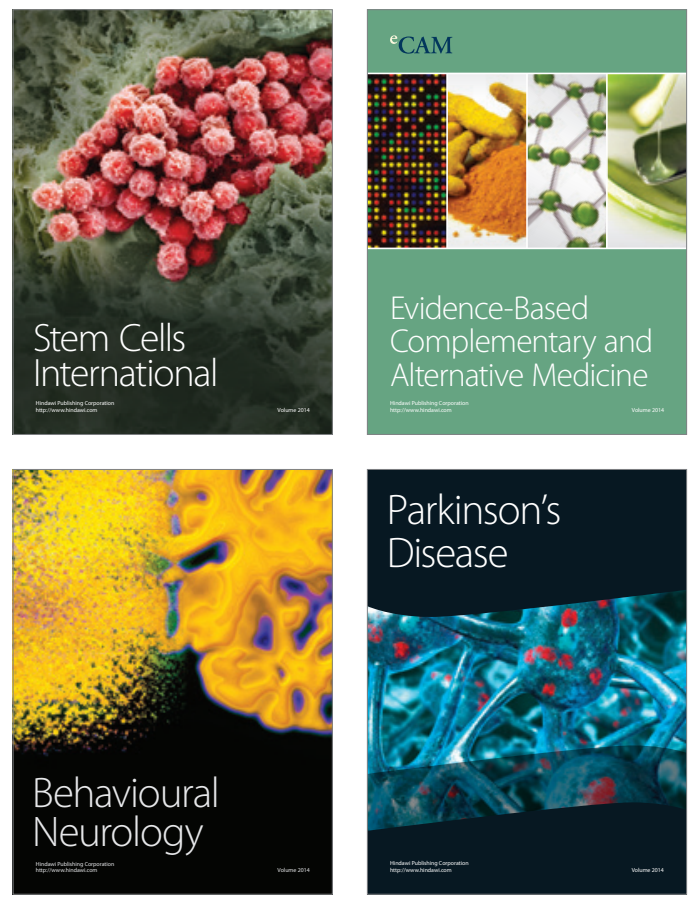
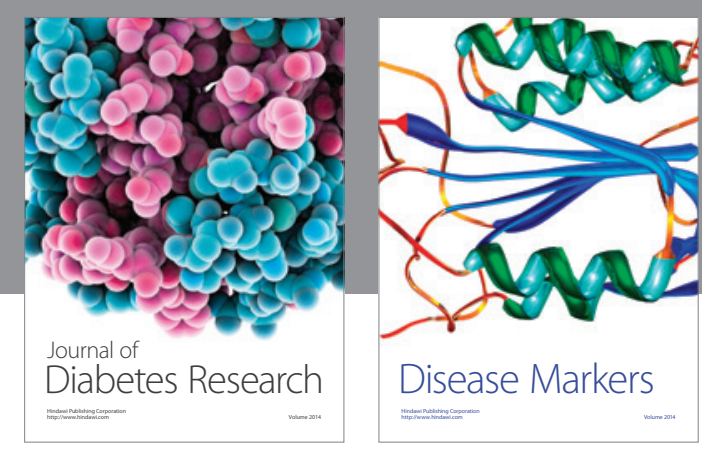

Disease Markers
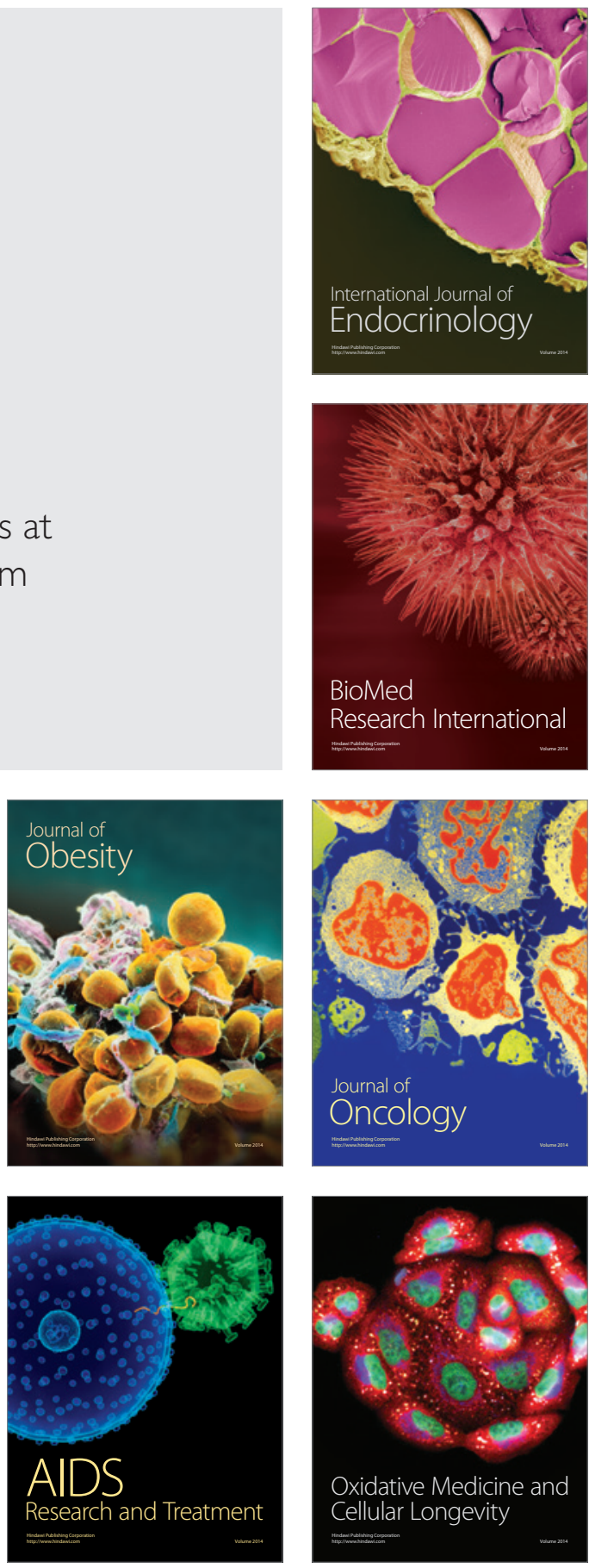